Original article

\title{
Reproductive features and use of an anti-inflammatory drug in estrus-induced dairy goats artificially inseminated in a standing position with cervix immobilization
}

\author{
Jeferson Ferreira Fonseca ${ }^{\mathrm{a}, *}$, Gilmar Pereira Alvim ${ }^{\mathrm{b}}$, \\ Joanna Maria Gonçalves Souza-Fabjann ${ }^{c, d}$, Maria Emília Franco Oliveira ${ }^{\mathrm{e}}$, \\ Viviane Lopes Brair ${ }^{\mathrm{d}}$, Felipe Zandonadi Brandãoc ${ }^{\mathrm{c}}$, Olivardo Facóa \\ a Embrapa Goats and Sheep, CP 145, Três Lagoas Farm, Road Sobral-Groaíras, km 04, Sobral, CE, CEP: 62010-970, Brazil \\ ${ }^{\circ}$ Embrapa Dairy Cattle, Road MG 133, km 42, Coronel Pacheco, MG, CEP: 36.155-000, Brazil \\ ' Faculty of Veterinary Medicine, Fluminense Federal University, Av. Vital Brasil Filho, 64, CEP 24230-340, Niterói, RJ, Brazil \\ ${ }^{\mathrm{d}}$ Faculty of Veterinary Medicine, School of Health Sciences, Universidade do Grande Rio, Rua Prof. José de Souza Herdy, 1160, 25071-202, Duque de Caxias, RJ, \\ Brazil \\ e Department of Preventive Veterinary Medicine and Animal Reproduction, College of Agricultural and Veterinary Sciences, São Paulo State University, \\ Jaboticabal, SP, CEP: 14.884-900, Brazil
}

\section{A R T I C L E I N F O}

\section{Article history:}

Received 29 March 2017

Received in revised form 6 June 2017

Accepted 9 July 2017

Available online 21 July 2017

\section{Keywords:}

Artificial insemination

AI technique

Caprine

Fertility

Ovulation

\section{A B S T R A C T}

This study evaluated reproductive features and role of Flunixin-Meglumine at timed artificial insemination $(\mathrm{AI})$, using a new technique of standing position with cervix immobilization. In Experiment 1,10 goats ( $n=5$ nulliparous [Null] and 5 pluriparous [Plu]) were evaluated after estrus induction by recorded reproductive parameters to define the ideal time for AI. In Experiment 2, goats were artificially inseminated 51-54 h after sponge removal with frozen-thawed semen. At AI, $1 \mathrm{~mL}$ saline (CONTROL; 18 Null and $14 \mathrm{Plu}$ ) or $50 \mathrm{mg}$ Flunixin-Meglumine (FLUNIXIN; 15 Null and $18 \mathrm{Plu}$ ) was administered i.m. Location of semen deposition was recorded for both groups. In Experiment 1, all sexual behavior and ovulatory parameters were similar between Null and Plu for estrus response and ovulation (100\%), interval from sponge removal to ovulation $(\sim 64.2 \mathrm{~h})$, largest ovulatory follicle diameter $(\sim 6.6 \mathrm{~mm})$, and number of ovulations ( 2.0). In Experiment 2, pregnancy rate was superior $(\mathrm{P}<0.01)$ for $\mathrm{CONTROL}$ (62.5\%; 10 Null and $10 \mathrm{Plu}$ ) than FLUNIXIN (30.3\%; 3 Null and $7 \mathrm{Plu}$ ) goats. Regardless of the treatment, intrauterine AI was more frequent $(\mathrm{P}<0.01)$ in Plu $(100.0 \% ; 32 / 32)$ than in Null $(69.7 \% ; 23 / 33)$ goats. Moreover, AI was more time-consuming $(\mathrm{P}<0.01)$ in Null $(44 \pm 37 \mathrm{~s} ; 4-139 \mathrm{~s})$ than in Plu $(21 \pm 19 \mathrm{~s}, 4-$ $78 \mathrm{~s})$ goats. Therefore, administration of Flunixin-Meglumine at the time of AI adversely affected pregnancy rate. High rates of intrauterine cervical penetration were obtained, achieving good pregnancy rates in goats not receiving Flunixin-Meglumine.

(C) 2017 Society for Biology of Reproduction \& the Institute of Animal Reproduction and Food Research of Polish Academy of Sciences in Olsztyn. Published by Elsevier Sp. z o.o. All rights reserved.

\section{Introduction}

In Brazil, goats are raised by both families and businesses, and goat production is an important part of society and agriculture [1]. Alpine, Anglo Nubian, Saanen, and Toggenburg are the main breeds explored for milk production, especially in the tropical area of southeast to northeast regions of the country. The Capragene, a genetic improvement program based on artificial insemination

\footnotetext{
* Corresponding author.

E-mail address: jeferson.fonseca@embrapa.br (J.F. Fonseca).
}

and progeny testing has been developed in Brazil [2]. To reach the goal, associated reproductive techniques needed to be developed. Focus was concentrated on control of the estrus cycle in dairy goats under tropical conditions, including protocols for estrus synchronization and induction, and a new artificial insemination (AI) technique was developed [3].

AI represents a safe and efficient form of reproduction and genetic improvement. Since the first report of AI in Brazil in the 1940s, there have been many examples of successful AI in goats by using a traditional bipedal position; however, unsatisfactory results have also been reported; the main cause of these results was intrauterine semen deposition efficiency [4,5]. In fact, 
intrauterine semen deposition and vaginal evaluation at the moment of AI are key factors affecting the establishment of pregnancy in goats [6]. Another important factor is the time required to perform $\mathrm{AI}$; procedures that require more time for handling the animal are more difficult for technicians as well as for the animals and helpers. For more than a decade, Embrapa team has been focused on developing an alternative AI technique called the "Embrapa AI technique," which has not yet been described in detail in the literature. In the traditional technique, the goat is upside down in anterior bi-pedal position, and the Duckbill speculum is inserted to locate the cervix [7]. Conversely, in the Embrapa technique, the goat stays in a standing position, the Collins speculum is used, and the cervix is immobilized with Allis forceps.

Especially when using vaginal devices for estrus synchronization, inflammatory processes can occur, and vaginal mucus was recognized to be deleterious to spermatozoa [8]. This negative effect could be increased if these contents are carried into the cervix and uterus, which can be facilitated by the traditional bipedal technique. Moreover, it is noteworthy that the traditional technique is much more tiring and uncomfortable for the goat and for the helper holding it. Although the goat does not express any discomfort, the use of an anti-inflammatory could overcome any possible degree of pain from the need to clamp the cervix when using the Embrapa technique. Thus, the administration of antiinflammatory agents during AI could provide a better rate of comfort and animal welfare to the females. Flunixin-Meglumine is a nonsteroidal anti-inflammatory drug commonly used for analgesic purposes. However, it is essential to detect any beneficial or harmful effect of such drug on ovulation, AI quality, and subsequent fertility of female goats.

Therefore, the present study aims (1) to assess the sexual behavior and ovulatory parameters in nulliparous and pluriparous Saanen goats after receiving a short-term estrus induction treatment to determine the ideal moment for AI for each category; (2) to describe an alternative AI technique in goats in a standing position with cervical immobilization; and (3) to evaluate the role of administering Flunixin-Meglumine at the moment of timed AI on pregnancy rate in goats.

\section{Materials and methods}

\subsection{Ethics and experimental conditions}

This study was approved by the Animal Care Committee of Fluminense Federal University (protocol number 116/11), and it was conducted according to the principles of the Brazilian Society of Laboratory Animal Science. The study was conducted during the anestrous season in Coronel Pacheco, Minas Gerais, in the southeast region of Brazil. The research unit is located at $435 \mathrm{~m}$ altitude and $S 21^{\circ} 35^{\prime}$ and $\mathrm{W} 43^{\circ} 15^{\prime}$. The area receives an average annual precipitation of $1581 \mathrm{~mm}^{3}$. The average annual temperature at site is $21^{\circ} \mathrm{C}$. Animals were housed with intensive management, receiving triturated Napier grass (Pennisetum purpureum) and a protein concentrate according to maintenance demand. Mineralized salt and water were offered ad libitum. A total of 84 Saanen goats were used, 43 nulliparous (Null) and 41 pluriparous (Plu) lactating goats at middle to end of lactation. Goats were allocated in two experiments.

\subsection{Experiment 1}

Ten goats (five Null and five Plu) were subjected to an estrus induction treatment and evaluated regarding their sexual behavior and ovarian parameters by ultrasonography to determine the optimal time to perform AI for both categories. Goats received an intravaginal sponge containing $60 \mathrm{mg}$ medroxyprogesterone acetate (MAP; Progespon ${ }^{\circledR}$, Syntex S.A., Industria Bioquímica y Farmacéutica, Buenos Aires, Argentina) that was maintained for $6 \mathrm{~d}$. An administration of $30 \mu \mathrm{g}$ d-cloprostenol (Prolise ${ }^{\circledR}$, ARSA S.R. L., Buenos Aires, Argentina) i.m. was performed at sponge insertion (day 0) plus 200 IU equine chorionic gonadotrophin (eCG; Novormon $^{\circledR} 5000$, Syntex S.A., Industria Bioquímica y Farmacéutica, Buenos Aires, Argentina) i.m. $24 \mathrm{~h}$ before sponge removal (day 5). All hormonal procedures were done between 6:00 and 7:00 am. Goats were subjected to a teaser male after sponge removal, twice a day (7:00 am and 6:00 pm), for $4 \mathrm{~d}$ until they showed no more estrus signs. Females were considered to be in estrus when allowed to be mounted.

\subsection{Experiment 2}

The same estrus induction protocol was applied in Experiment 2. A total of 65 goats ( 33 Null and $32 \mathrm{Plu}$ ) were assigned according to parity, body weight, and condition score (BCS; scale $1-5$ ) to two treatment groups: FLUNIXIN ( $51.8 \pm 8.9 \mathrm{~kg}$ and $3.1 \pm 0.6$ of BCS $)$ and CONTROL $(52.0 \pm 8.7 \mathrm{~kg}$ and $3.1 \pm 0.5$ of BCS $)$. Goats were artificially inseminated (AI) $51-54 \mathrm{~h}$ after sponge removal with frozenthawed $0.25 \mathrm{~mL}$ straws $\left(100 \times 10^{6}\right.$ spermatozoa $)$. At the moment of AI, goats received either Flunixin-Meglumine $(1 \mathrm{~mL}, 50 \mathrm{mg}$; Banamine $^{\circledR}$, Schering-Plough, Cotia, Brazil, $n=33,15$ Null and 18 Plu) or saline ( $1 \mathrm{~mL}$, control group, $n=32,18$ Null and $14 \mathrm{Plu}$ ) intramuscularly.

\subsection{Ultrasonography}

Transrectal ovarian ultrasonography was performed in all goats of Experiment 1 by the same operator. Ultrasound assessments were performed every $8 \mathrm{~h}$ from sponge removal until ovulation in all goats. Ovulation was confirmed in a subsequent evaluation $8 \mathrm{~h}$ after ovulation detection. The examinations were conducted with a B-mode transrectal ultrasonographic scanner (KX 2000G Vet ${ }^{\mathbb{R}}$, Kaixin, Xuzhou, China) with $7.5 \mathrm{MHz}$ transducer fitted to a plastic rod that allowed the transrectal manipulation of the probe. Does were maintained in a standing position, fecal pellets were removed manually (with a finger), and $20 \mathrm{~mL}$ of carboxymethyl cellulose gel was placed into the rectum with a syringe. Ovaries were located as previously described [9], and the number, diameter, and position of ovarian follicles $\geq 3 \mathrm{~mm}$ in size were recorded. The day of ovulation was defined as the day when the largest follicle, previously identified, was no longer detected. The preovulatory follicle diameter was considered the last measurement obtained before ovulation. Approximately $60 \mathrm{~d}$ after AI (Experiment 2), the same equipment was used to check pregnancy.

\subsection{Artificial insemination technique}

The Embrapa technique of transcervical AI through cervical immobilization was applied. Goats were contained in the milking room in a standing position, allowing the inseminator to stand. Another person maintained elevation of the goat's tail while the inseminator cleaned the external genitalia of the animal with a dry paper towel (Fig. 1A). At the end of this stage, the inseminator stimulated the clitoris, massaging the bottom of the vulva with the paper towel avoiding direct contact with the animal.

Collin-type specula are used in sizes $0-3$. In the case of nulliparous goats, speculum 0 was first inserted and gently opened to provide vaginal dilation, facilitating the introduction of speculum 1. In most cases, speculum 1 was the appropriate choice for young goats. For pluriparous ones, speculum 2 was the appropriate choice. The speculum was lubricated by applying nonspermicidal gel (Fig. 1B) before insertion through the vulva and 


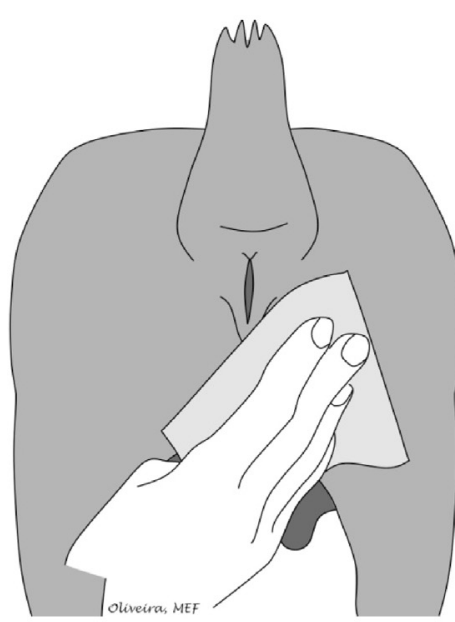

A

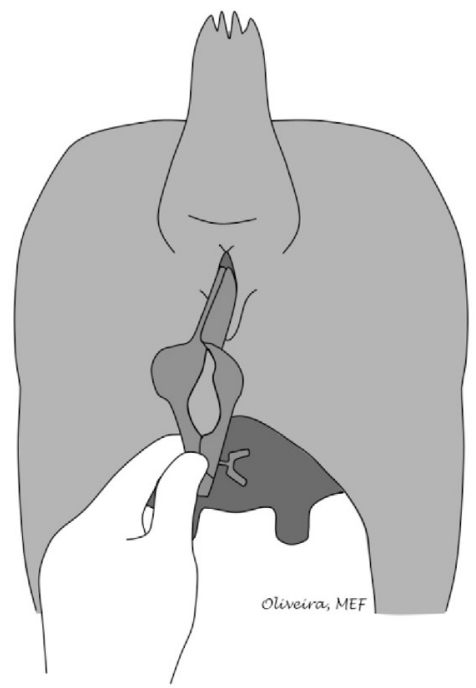

$\mathrm{C}$

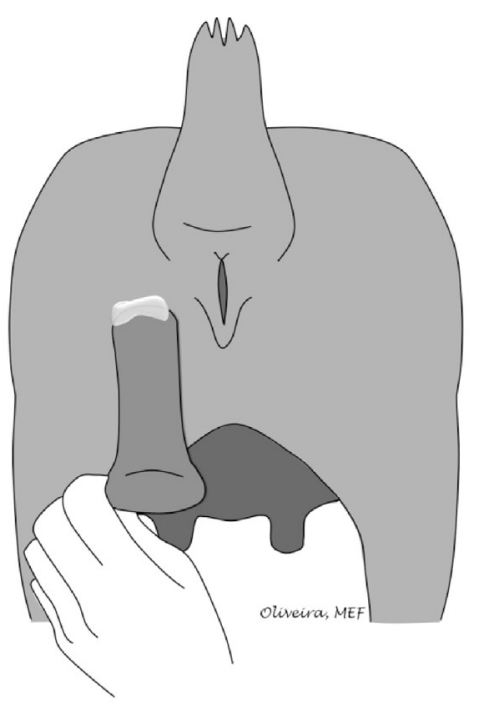

B

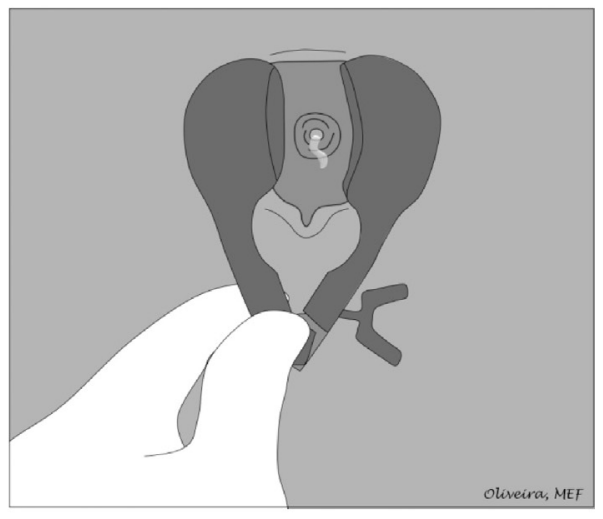

$\mathrm{D}$

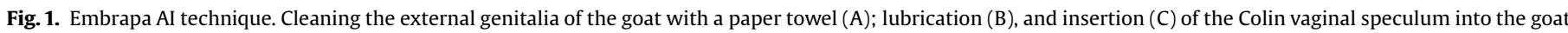
vagina; cervical visualization and mucus discharge (D).

vagina to facilitate penetration (Fig. 1C). The mucus classification could be performed at this time (Fig. 1D). With the aid of a light source (e.g., a penlight), speculum was open until reaching the center of the vagina when the cervical ostium projected into the speculum. When the speculum size did not allow it to be opened, or if the vaginal wall protruded into the speculum, hampering cervix visualization, the speculum size was changed for one smaller or greater, respectively.
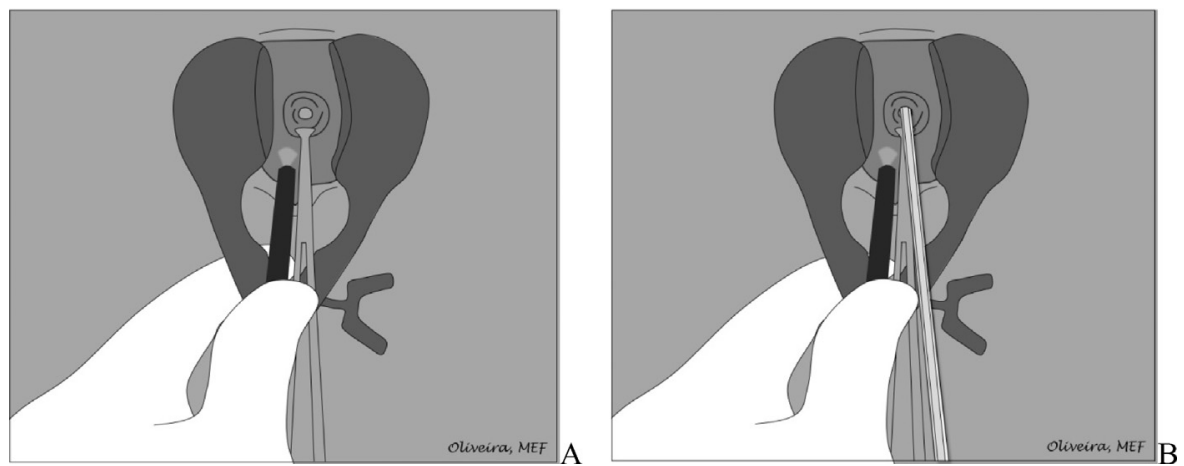

Fig. 2. Cervical immobilization with Allis forceps and light source (A); cervical transposition with the semen applicator (B). Note the handling of the instruments (forceps, speculum, and light source). 
A 26-cm Allis-type clamp devoid of head milling initially used was changed by special developed forceps (Embrapa ${ }^{\circledR}$ forceps for Cervical Immobilization and Artificial Insemination in Small Ruminants; Brasilia - DF, Brazil). After visualization of the cervix, it was inserted into and under the cervical pathway. The clamp has a ratchet that was pressed so that only the necessary position to immobilize cervix was locked. This procedure was done when the cervix was well visualized and immediately before the passage of the French semen applicator. After cervix immobilization, the inseminator held the speculum, the light source, and the clamp with one hand. This set was not to be pulled (Fig. 2A). With the other hand, the inseminator introduced the semen applicator into the cervical orifice (Fig. 2B), making lateral-lateral (sideways) and cranio-ventral (up and down) movements with light and forward cranial pressure. The distance and number of passed cervical rings were recorded. Cranial pressing was stopped when loss of resistance was detected. The semen was then deposited (Fig. 3). Time consumed (seconds) and location of semen deposition (SD) were recorded according to length $(\mathrm{cm})$ of applicator introduction and cervical ring surpassed as SD $0(0 \mathrm{~cm} /$ pericervical or superficial), SD 1 (1-2 cm/first ring), SD 2 ( $2-3 \mathrm{~cm} / \mathrm{s}$ ring), SD 3 (3-4 cm/third ring), SD $4(4-5 \mathrm{~cm} /$ fourth ring), and SD 5 (intrauterine). Independently from length and number of cervical rings surpassed, uterine insemination was considered performed when total cervical rings were transposed.

After semen deposition, the specula and clamps were immediately removed, washed with detergent in water and placed in boiling water for at least $1 \mathrm{~min}$. After that, the instruments were placed in a receptacle containing filtered water with $1 \%$ nontoxic sanitizing agent for cooling. Only after all of these sterilization procedures were complete the instruments were used in another animal.

\subsection{Statistical analysis}

Statistical analysis was performed using all tests for statistical significance at the $95 \%$ confidence interval. A tendency was considered when $P$ value was $>0.05$ and $<0.10$ significance. Pearson correlation was calculated among the variables. Percentages were compared by using the Chi-square test. Quantitative data were recorded as mean $\pm S D$, subjected to one-way analysis of variance, and compared by Tukey test using a SAEG program (System for Statistical Analysis) [10].

\section{Results}

\subsection{Experiment 1}

The ovarian and behavioral parameters of nulliparous and pluriparous goats are listed in Table 1 . All parameters were similar $(P>0.05)$ for both categories. Interestingly, a significant positive Pearson correlation $(r=0.73, \mathrm{P}<0.05)$ was found between the BCS and the total number of ovulations. BCS was similar $(\mathrm{P}>0.05)$ to nulliparous $(3.3 \pm 0.1)$ and pluriparous $(3.4 \pm 0.3)$ groups.

\subsection{Experiment 2}

Pregnancy rates after AI, according to semen deposition site, are presented in Table 2. Regardless of the category, a total of $84.4 \%$ $(27 / 32)$ and $84.8 \%(28 / 33)$ of intrauterine AI was achieved in the CONTROL and the FLUNIXIN groups, respectively $(P>0.05)$. Cervical transposing was performed in $33 \pm 32 \mathrm{~s}$ (4-121 s) and $32 \pm 31 \mathrm{~s}(4-139 \mathrm{~s})$ for CONTROL and FLUNIXIN, respectively $(\mathrm{P}>0.05)$.

The effect of category on pregnancy rate is recorded in Table 3. Cervical transposing was more time-consuming $(\mathrm{P}<0.01)$ in Null (44 \pm 37 s; $4-139 \mathrm{~s})$ than in Plu ( $21 \pm 19 \mathrm{~s}, 4-78)$ goats. Intrauterine AI was more frequent $(\mathrm{P}<0.01)$ in Plu $(100.0 \% ; 32 / 32)$ than in Null (69.7\%; 23/33) goats.

\section{Discussion}

Experiment 1 was conducted to determine the estrus behavior and ovulatory responses in estrus-induced Saanen goats to serve as

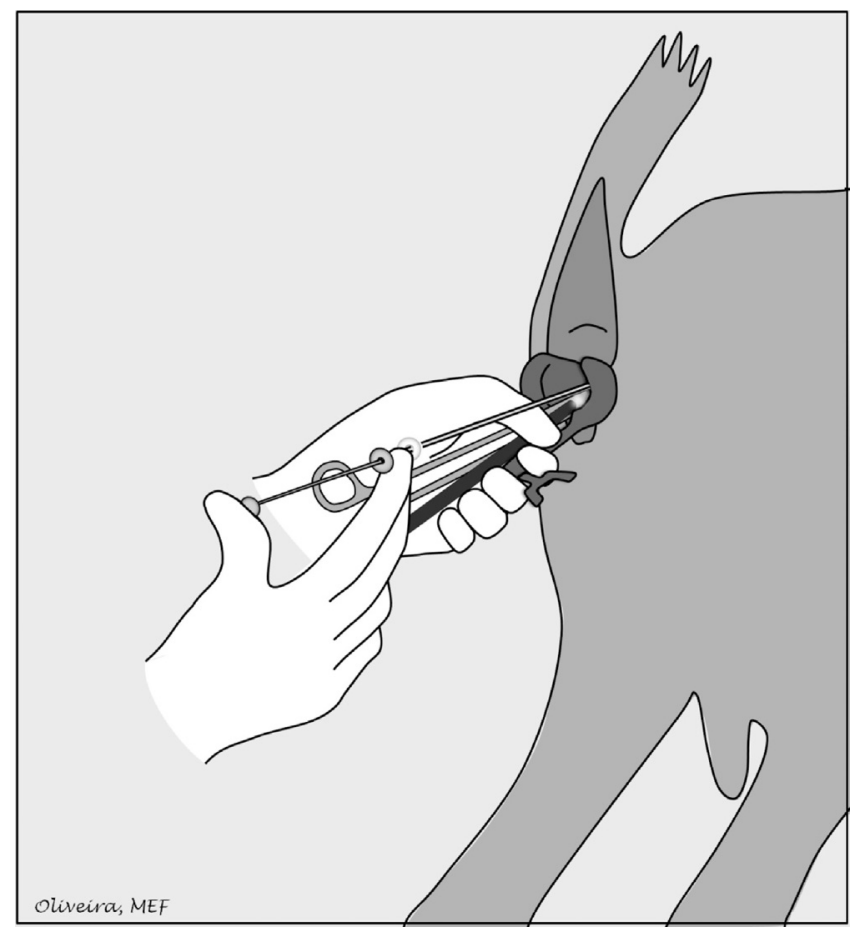

Fig. 3. Final view of the Embrapa AI technique in goats by means of cervical immobilization. 
Table 1

Behavioral and ovarian follicular parameters of Saanen goats subjected to estrus synchronization treatment (Mean \pm SD or \%).

\begin{tabular}{|c|c|c|c|}
\hline Parameter & Nulliparous & Pluriparous & Total \\
\hline Number of animals & 5 & 5 & 10 \\
\hline Estrus response (\%) & 100.0 & 100.0 & 100.0 \\
\hline Goats ovulating (\%) & 100.0 & 100.0 & 100.0 \\
\hline Interval from sponge removal to estrus (h) & $43.2 \pm 6.6$ & $48.0 \pm 14.7$ & $45.6 \pm 11.0$ \\
\hline Interval from sponge removal to ovulation (h) & $63.6 \pm 15.6$ & $64.8 \pm 13.0$ & $64.2 \pm 13.6$ \\
\hline Interval from estrus onset to ovulation (h) & $18.0 \pm 6.0$ & $16.8 \pm 5.0$ & $17.4 \pm 5.2$ \\
\hline Diameter of large preovulatory follicles ( $\mathrm{mm})$ & $6.7 \pm 0.9$ & $6.5 \pm 0.4$ & $6.6 \pm 0.7$ \\
\hline Number of ovulations & $1.8 \pm 0.4$ & $2.2 \pm 0.8$ & $2.0 \pm 0.7$ \\
\hline
\end{tabular}

$\mathrm{P}>0.05$.

Table 2

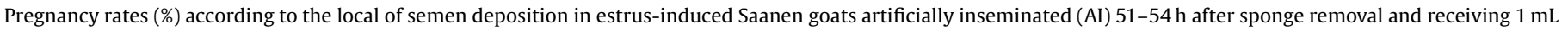
saline (CONTROL) or $50 \mathrm{mg}$ Flunixin-Meglunine (FLUNIXIN) i.m. at the time of AI.

\begin{tabular}{|c|c|c|c|c|}
\hline Depth $(\mathrm{cm})$ & CONTROL & FLUNIXIN & Total & $P$ value \\
\hline $0 \mathrm{~cm}(0 / \text { pericervical })^{1}$ & $50.0(1 / 2)$ & $0.0(0 / 3)$ & $20.0(1 / 5)$ & - \\
\hline $1-2 \mathrm{~cm}(1 / \text { Superficial cervical })^{1}$ & $0.0(0 / 1)$ & $0.0(0 / 1)$ & $0.0(0 / 2)$ & - \\
\hline $2-3 \mathrm{~cm}(2 / \text { Initial cervical })^{1}$ & $100.0(1 / 1)$ & $0.0(0 / 1)$ & $50.0(1 / 2)$ & - \\
\hline $3-4 \mathrm{~cm}(3 / \text { Intermediate cervical })^{1}$ & $100.0(1 / 1)$ & $0.0(0 / 0)$ & $100.0(1 / 1)$ & - \\
\hline $5 \mathrm{~cm}(5 / \text { Uterine })^{1}$ & $62.9^{\mathrm{a}}(17 / 27)$ & $35.7^{\mathrm{b}}(10 / 28)$ & $49.1(27 / 55)$ & 0.043 \\
\hline Total & $62.5^{\mathrm{a}}(20 / 32)$ & $30.3^{\mathrm{b}}(10 / 33)$ & $46.1(30 / 65)$ & 0.009 \\
\hline
\end{tabular}

() Number of females pregnant/Number of females inseminated.

a,b Percentages with different superscripts within a row differed (Chi-Square test).

${ }^{1}$ Cervical rings surpassed/locale of semen deposition.

Table 3

Pregnancy rates (\%) in estrus-induced Saanen goats artificially inseminated (AI) 51$54 \mathrm{~h}$ after sponge removal and receiving $1 \mathrm{~mL}$ saline (CONTROL) or $50 \mathrm{mg}$ FlunixinMeglunine (FLUNIXIN) i.m. at the time of AI.

\begin{tabular}{lllll}
\hline Category & CONTROL & FLUNIXIN & Total & P value \\
\hline Nulliparous & $55.5^{\mathrm{a}}(10 / 18)^{1}$ & $20.0^{\mathrm{b}}(3 / 15)$ & $39.4(13 / 33)$ & 0.037 \\
Pluriparous & $71.4^{\mathrm{a}}(10 / 14)$ & $38.9^{\mathrm{a}}(7 / 18)$ & $53.1(17 / 32)$ & 0.067 \\
Total & $62.5^{\mathrm{a}}(20 / 32)$ & $30.3^{\mathrm{b}}(10 / 33)$ & $46.1(30 / 65)$ & 0.009 \\
\hline
\end{tabular}

${ }_{\mathrm{a}, \mathrm{b}}$ Percentages with different superscripts within a row differed (Chi-square test).

1 () Number of females pregnant/Number of females inseminated.

a basis for Experiment 2. Both estrus response and ovulation rate were overall $100 \%$, highlighting the efficiency of the treatment chosen. The interval from sponge removal to estrus $(\sim 45.6 \mathrm{~h})$ and to ovulation $(\sim 64.2 \mathrm{~h})$, interval from estrus onset to ovulation $(\sim 17.4 \mathrm{~h})$ and diameter of largest preovulatory follicle $(\sim 6.6 \mathrm{~mm})$ were similar between nulliparous and pluriparous goats. Both categories were thus artificially inseminated at 51-54h after sponge removal, to allow adequate sperm capacitation and acrosome reaction. The number of ovulations was 1.8 (Null) and 2.2 (Plu), the latter being slightly higher than 1.8 (Plu) earlier reported for Saanen goats [11]. It is well known that BCS can affect the number of ovulations and, in the current study, there was a positive correlation $(r=0.73)$ between both variables, emphasizing the importance of good nutrition for reproduction. It also emphasizes the need of equal assigning based on BCS when studying reproductive features.

The knowledge about the estrus induction protocol in relation to local goat behavioral and ovarian parameters is essential to reach success in a timed AI program. Exp. 1 revealed intervals of 64 and $17 \mathrm{~h}$ from sponge removal and from estrus onset to ovulation, respectively, in Saanen goats. In Alpine goats, we also reported intervals of 59 and $26 \mathrm{~h}$ from sponge removal and from estrus onset to ovulation, respectively [12]. In the Exp. 2, the time of AI was chosen based on these parameters. Considering the conception rate in the CONTROL group (62.5\%), this choice appeared to have been correct. Then, considering the previous reported protocol [13] and the preconized time to AI of the present study, good conception rates are expected.

As previously described, the administration of FlunixinMeglumine at AI was applied to provide a better rate of comfort and animal welfare to the females. Flunixin-Meglumine is a nonsteroidal anti-inflammatory drug used for analgesic purposes, among others. Its mechanism of action is the inhibition of cyclooxygenase, responsible for the synthesis of the whole cascade of prostaglandins, which are derived from arachidonic acid [14]. It is well known that ovulation is the central event of ovarian physiology and that nonsteroidal anti-inflammatory drugs can interfere with this phenomenon [15]. In the present study, the use of Flunixin-Meglumine adversely affected the pregnancy rate, especially in Null goats. It is known that PGF, PGE 2, and PGF2 $\alpha$ have important roles in the early reproductive stages, ovulation, endometrial vascularization, blastocyst hatching, and embryo implantation mechanisms [16,17]. In mares, the administration of Flunixin-Meglumine during the periovulatory period blocked ovulation leading to a great percentage of luteinized, unruptured follicles, depending on the time relative to expected hCG-induced ovulation [18]. We expected that at the time of FlunixinMeglumine administration, the cascade of ovulation was already initiated and thus would not be affected by this drug. However, although not measured in the present study, Flunixin-Meglumine possibly adversely affected ovulation and subsequently pregnancy rate in goats from FLUNIXIN group.

In the current study, the Embrapa AI technique resulted in high rates of intrauterine cervical $(\sim 84.6 \%)$ penetration, regardless of animal category, achieving a $62.5 \%$ pregnancy rate in the CONTROL group. The rate of intrauterine AI obtained in the present study was comparable to the $60 \%$ reported by Sohnrey and Holtz [7] applying the traditional technique. Under Brazilian tropical conditions, Andrade [4] reported that out of 17 superficial cervical AIs performed, only $29 \%$ resulted in pregnancy, whereas deep cervical $(n=29)$ and uterine $(n=20)$ inseminations resulted in pregnancy in $45 \%$ and $58 \%$ of cases, respectively. In addition, Frazão Sobrinho et al. [5] reported 13 superficial, 17 deep cervical, and 10 uterine AIs, resulting in pregnancies in $23.1 \%, 23.5 \%$, and $70.0 \%$ of cases, 
respectively. Salvador et al. [19] reported only $17.5 \%$ post-cervical insemination in Murciano Granadina goats. The closer the semen deposition is to the fertilization site, the higher the rate of pregnancy, especially when using frozen-thawed semen. The goal of AI, according to semen deposition by the transcervical method, should be to reach the uterine body, resulting in intrauterine insemination. Taken together, these highly variable results indicate the difficulty of the AI technique used by authors to deposit semen in the uteruses of goats. The AI technique described and used in the present study appear to have solved this crucial and important key aspect of AI.

The performance time during the procedure can be an indicator of the success and efficiency of the AI technique. AI performed very quickly should observe the applicator degree of penetration. Insemination deeper than $3 \mathrm{~cm}$ may likely reach the uterus body and does not need to be more than $5 \mathrm{~cm}$ long. Technical faults during traditional AI, with anterior bipedal support, can cause perforation of the uterus or, more commonly, intracornual insemination, which also is not desired because it is not generally known from which ovary ovulation will occur. On the other hand, runtime must be considered because there is a direct relationship between the duration of insemination and the resulting rate of pregnancy. Andrade [4] found that of the $43.2 \%$ of animals that were inseminated by the traditional technique (with anterior biped support) in less than $5 \mathrm{~min}, 58 \%$ of them became pregnant, and of the other $56.8 \%$ that were inseminated between 5 and 10 min, only $48 \%$ became pregnant.

In general, under our experimental conditions, the sexual behavior and ovulatory parameters were similar between nulliparous and pluriparous Saanen goats after receiving a short-term estrus induction protocol. Understanding these parameters is necessary for choosing the optimal time to perform AI in dairy goats. The administration of Flunixin-Meglumine at the moment of AI adversely affected the pregnancy rate, especially in nulliparous goats. Finally, the Embrapa AI technique resulted in satisfactory rates of cervical transposing and intrauterine $\mathrm{AI}$, achieving reasonable pregnancy rates in goats not receiving FlunixinMeglumine.

\section{Conflicts of interest}

The authors have no conflicts of interest to declare.

\section{Acknowledgments}

This study was supported by the National Council for Scientific and Technological Development (CNPq; Projects 310166/2012-8 and 479826 2013-7), Fundação de Amparo à Pesquisa de Minas Gerais (Fapemig; Project CVZ-PPM 00042-14), and EMBRAPA
(Project 02.08.02.005.00.04). The authors also thank CAPRIMA (Associação de Criadores de cabras Leiteiras da Zona da Mata - MG) for providing animals and animal housing conditions. FZB, MEFO, and JFF are fellows of the CNPq and JMGSF of CAPES.

\section{References}

[1] Lôbo RNB, Facó O, Bezerra Oliveira Lôbo AMB, Vasques Villela L. Brazilian goat breeding programs. Small Rumin Res 2010;89:149-54.

[2] Facó O, Lôbo RNB, Guimarães Gouveia AM, Mattos de Paiva Guimarães MPSL, Fonseca JF, Santos TNM, et al. Breeding plan for commercial dairy goat production systems in southern Brazil. Small Rumin Res 2011;98:164-9.

[3] Fonseca JF, Alvim GP, Lobo Ambo, Facó O. Técnica Embrapa de inseminação Artificial transcervical em caprinos por meio de fixação cervical. Embrapa Caprinos e Ovinos. Circular Técnica 2011;43.

[4] Andrade JS. Sêmen caprino congelado: efeito de dois diluentes sobre a taxa de fertilidade. Belo Horizonte: Escola de Veterinária UFMG; 199653 f. [Masters dissertation], In Portuguese. Abstract in English.

[5] Frazão Sobrinho JM, Vieira RJ, Macedo N, Cavalcante VC, Silva JM. Fertilidade de cabras SRD inseminadas por via transcervical de acordo com o local de deposição do sêmen e número de inseminações. Proceedings of the 2 . CONERA, 2005. In Portuguese. Abstract in English.

[6] Arrebola FA, Pardo B, Sanchez M, Lopez MD, Perez-Marin CC. Factors influencing the success of an artificial insemination program in Florida goats. Span J Agric Res 2012;10:338-44.

[7] Sohnrey B, Holtz W. Technical note: transcervical deep cornual insemination of goats. J Anim Sci 2005;83:1543-8.

[8] Manes J, Ríos G, Fiorentino MA, Ungerfeld R. Vaginal mucus from ewes treated with progestogen sponges affects quality of ram spermatozoa. Theriogenology 2016;85:856-61.

[9] Ginther OJ, Kot K. Follicular dynamics during the ovulatory season in goats. Theriogenology 1994;42:987-1001.

[10] Ribeiro Júnior I. Análises estatísticas no SAEG. Viçosa: Editora UFV; 2001 301p..

[11] Souza JMG, Couto JF, Bruschi JH, Viana JHM, Camargo LSA, Fonseca JF. Estrus and ovulation in anestrous Saanen Goats submitted to short-term estrous induction protocols. XXI annual meeting of the Brazilian Embryo Technology Society, Costa do Sauípe. Proceedings of XXI annual meeting of the Brazilian Embryo Technology Society. Porto Alegre: Acta Sci Vet 2007; 35:1289.

[12] Fonseca JF, Souza JMG, Bruschi JH, Viana JHM, Brandão FZ, Silva WJ, et al. Induction of estrus in cyclic Alpine goats with short-term progesterone protocols with or without eCG administration. Reprod Fert Dev 2010;22:169.

[13] Fonseca JF, Bruschi JH, Santos ICC, Viana JHM, Magalhães ACM. Induction of estrus in non-lactating dairy goats with different estrous synchrony protocols. Anim Reprod Sci 2005;85:117-24.

[14] Vane JR, Botting RM. Overview - mechanisms of action of anti-inflammatory drugs. Improved nonsteroidal anti-inflammatory drugs. COX-2 enzyme inhibitors. London: Kluwer Academic Publishers and William Harvey Press; 1996. p. 1-27.

[15] Gaytán M, Morales C, Bellido C, Sánchez-Criado JE, Gaytán F. Non-steroidal anti-inflammatory drugs (NSAIDs) and ovulation: lessons from morphology. Histol Histopathol 2006;21:541-56.

[16] Tsafriri A, Lindner HR, Zor U, Lamprecht SA. Physiological role of prostaglandins in the induction of ovulation. Prostaglandins 1972;2:1-10.

[17] Sayre BL, Lewis GS. Cervical dilation with exogenous oxytocin does not affect sperm movement into the oviducts in ewes. Theriogenology 1996:46:233-41.

[18] Cuervo-Arango J. The effect of treatment with flunixin meglumine at different times relative to hCG administration on ovulation failure and luteal function in mares. Anim Reprod Sci 2011;127:84-90.

[19] Salvador I, Viudes-de-Castro M, Bernacer J, Gómez E, Silvestre M. Factors affecting pregnancy rate in artificial insemination with frozen semen during non-breeding season in Murciano Granadina goats: a field assay. Reprod Domest Anim 2005;40:526-9. 